\title{
A model for reusing service knowledge based on an empirical case
}

\author{
S. Ahmed-Kristensen • G. Vianello
}

Received: 30 July 2013/Revised: 11 June 2014/Accepted: 29 June 2014/Published online: 4 October 2014

(C) The Author(s) 2014. This article is published with open access at Springerlink.com

\begin{abstract}
The reuse of knowledge and information arising from the different phases of a product's lifecycle is crucial for a company in order to achieve competitive advantage. This paper describes a case study from the oil industry investigating the transfer of knowledge within the service phase and also between the service and design phases. Interviews with engineering designers and service engineers were conducted. Knowledge arising from servicing the drilling equipment that was identified as relevant for service engineers was compared to that relevant for engineering designers. Furthermore, the mechanisms involved in the transfer of knowledge between service and design were investigated. Knowledge about changes, issues and improvements generated during service was found to be relevant to both groups; however, engineering designers were interested in knowledge of equipment at a component level whilst service engineers were more interested in obtaining an overview of the systems. The study showed that communication between the departments consisted prevalently of the service engineers pushing knowledge and information to the engineering designers. The reusing service knowledge (RSK) model is proposed based upon the findings and the understanding from a general framework for developing a knowledge management strategy. Additionally, the initial model was revised to explicitly address the factors that emerged from the case study. The RSK model was developed based on a case study from a customised industry; however, previous studies indicated
\end{abstract}

S. Ahmed-Kristensen $(\square) \cdot$ G. Vianello

Design Engineering and Innovation, Department of Management

Engineering, Technical University of Denmark, Building 426,

Produktionstorvet, 2800 Lyngby, Denmark

e-mail: sakr@dtu.dk that similar issues are also of relevance to a variant design industry.

Keywords Service Engineering changes $\cdot$ Knowledge management strategy $\cdot$ Engineering knowledge $\cdot$ Product lifecycle

\section{Introduction}

The general trend in engineering design is to consider issues regarding different phases of the product lifecycle during the design of a new product. Knowledge from the later phases and its feedback to the engineering design phases is important in product development as the transfer of operational experience to engineering designers facilitates the correction of product flaws and suggests directions for future improvements. Effective reuse of operational experience and systematic learning from past cases requires a company to adopt an effective knowledge management strategy that is designed to consider the characteristics of the product produced, the organisational structure and the support provided during service.

Moreover, as many manufacturing companies are moving their business strategy from simply selling products to also servicing them throughout their lifecycle, it is equally relevant to reuse the experience from past service interventions within the service phase itself, in order to improve the quality and the consistency of the service provided.

\subsection{Aim}

Companies capture a vast amount of information arising throughout a product's lifecycle and store it into 
repositories; however, a complete understanding of how to effectively reuse information from the latter phases of a products lifecycle and turn it into a factor of competitive advantage is still needed Ahmed and Vianello (2009).

This research focuses upon knowledge arising from the service phase of complex engineering products and proposes a model to facilitate the reuse of service knowledge both within the service phase and across phases of a product's lifecycle.

A case study approach was adopted, and a case study was conducted within the context of drilling equipment for the oil industry. The main research questions were as follows:

- What forms of knowledge arising from service are relevant for service engineers and engineering designers?

- How is knowledge transferred within service and from service to design?

The findings from the case study were applied to a framework for developing a knowledge management strategy from the literature. The result is a model for reusing knowledge from service both within the service phase and across phases of the product's lifecycle.

\section{Background}

\subsection{Knowledge definition}

Knowledge definition and classification is a topic of common interest to various disciplines with entire areas of philosophy specifically dedicated to debate this topic. In this paper, the approach towards knowledge suggested by von Krogh et al. (2001) has been adopted. They refer to the concept of knowledge domains, consisting of the set of relevant data, information, articulated and tacit knowledge in relation to a particular subject. The term "knowledge", as used in this paper, includes both explicit and tacit elements, whilst "information" is used interchangeably with codified knowledge and refers to documentation.

\subsection{Knowledge types}

Knowledge and information can be categorised in many ways (Zack 1999; Wallace et al. 2005), including:

- Declarative knowledge, knowledge describing something;

- Procedural knowledge, or know-how, how something occurs or is performed;

- Causal knowledge, knowledge about why something occurs.

Together with these forms of knowledge a fourth, supporting category, the "know of", ensure that the members of an organisation are aware of the existence of knowledge and information and are able to retrieve and reuse it.

This distinction between types of knowledge is important when considering the management of knowledge as, according to Zack (1999), the different types of knowledge are best processed by differing knowledge and information systems strategies.

\subsection{Knowledge transfer frameworks}

A large number of frameworks to transfer knowledge exist; two of these frameworks describing knowledge transfer were reviewed in detail and are discussed here: (1) Argote and Ingram (2000) and (2) Gilbert and Cordey-Hayes (1996). These were selected as two examples framework that fit with the research focus of moving knowledge from service to design, i.e. across domains, where Argote and Ingram (2000) describe the moving of reservoirs of knowledge and Gilbert and Cordey-Hayes (1996) as an example of how knowledge transfer occurs. Argote and Ingram (2000) proposed a framework based upon empirical evidence to describe the phenomenon of knowledge transfer. At the organisational level, three basic elements, i.e. tools, tasks and members, and the networks formed by their combination are identified as reservoirs of the organisation's knowledge. Tools represent the technological elements within the organisation; tasks represent the goal and purpose, whilst members are the individuals who form the organisation resources. The framework suggests that knowledge transfer can occur through two distinct mechanisms: the moving of a knowledge reservoir into different context or the modification of a reservoir at the recipient side. To have a positive impact on organisational performance, the networks formed by pairs of the three basic elements of the reservoirs must be compatible internally, within the network, and externally, with other networks within the organisation. From a management perspective, the aim of the knowledge transfer is to increase the competiveness of a company; hence, the ideal objective of the process is to enhance the company's internal knowledge in a way that is difficult to replicate for other companies. Argote and Ingram identify the network member-to-member as the reservoir that best fulfils this need, as the interactions between members of an organisation may be transferred within the organisation, although not easily, but they are not likely to be adapted to other organisations as they are influenced by the characteristics, routines and culture specific of the company.

The framework described above and summarised in Fig. 1 provides a general description of possible knowledge transfer mechanisms; however, it does not describe the different stages that constitute the knowledge transfer process or the forms of the knowledge that are relevant to 
Fig. 1 Argote et al.'s framework on knowledge transfer
Knowledge of organisation embedded in reservoirs (tasks, tools, members)

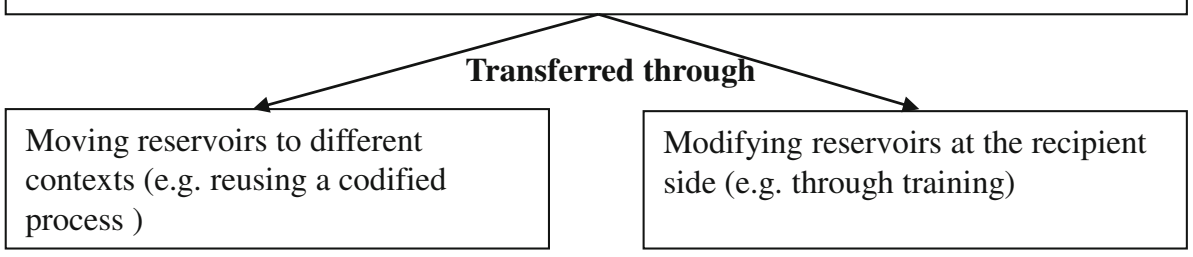

transfer in order to increase the competitiveness of the company.

Other authors propose frameworks that describe how knowledge transfer occurs. Specifically, Gilbert and CordeyHayes (1996) focus on subsequent phases of knowledge transfer, namely acquisition, communication, application and assimilation. They state that true learning occurs only in the last stage where the process results in the development of core organisational routines and practices, although the transfer of knowledge is already effective in the application phase. This vision of knowledge transfer is complementary to Argote and Ingram's model when transfer occurs though modifying knowledge at the receiver's side, but excludes transfer through moving knowledge reservoirs to other contexts.

Focusing on the communication aspects of knowledge transfer, knowledge sharing may be symmetric or asymmetric (Lin et al. 2005). In symmetric transfer, the sender and receiver of information share the benefits of the transfer, whilst in asymmetric transfer one party gains more benefits from the transfer of knowledge than the other. When asymmetric sharing occurs, the transfer process can be analysed through a sender-receiver framework that includes motivational issues, trust between parties involved and the completeness of the shared information.

The process of transferring knowledge across disciplines is thought to facilitate innovation as dissimilarity is a condition for learning and bringing together different perspectives supports the exploration of new solutions (March 1991). However, this involves more complex mechanisms than the simple transfer of knowledge within a homogeneous group. According to Carlile's framework for managing knowledge across boundaries, when a pragmatic boundary is present, that is when the parties have different interests, the simple transfer of available knowledge is not enough; it has to be translated according to the receiver's needs in order to be successfully shared (Carlile 2004). Hence, this is expected to be the case for this study and for the transfer of service knowledge between service and design phases.

\subsection{Knowledge management: industrial implications}

Research studies have generally adopted a positive approach towards knowledge management and organisational learning, claiming that firms with clear strategies in knowledge transfer are more successful than those without these and highlighting the importance for a company to be able to efficiently manage its internal knowledge in order to achieve competitive advantage (Zander and Kogut 1995). On the contrary, only a limited number of studies have described failures in managing knowledge and the related consequences (Storey and Barnett 2000). However, industrial practice shows that the development and implementation of a knowledge management strategy does not always lead to the expected positive effects. For instance, according to Lucier and Torsilieri (1997), $84 \%$ of knowledge management programmes fail to have a real impact. Robertson (2003) identified a number of recurrent issues in regard to knowledge management from the analysis of industrial practice, which include:

- Inconsistent and unstructured approach to information management;

- Lack of knowledge sharing across business units;

- Difficulties in determining and disseminating "best practices";

- Inconsistency in advice given by front-line staff;

- Over reliance on long-service members of staff as sources of knowledge;

- Cultural barriers between head office and regional staff.

Additionally, Robertson highlighted the problems when to implementing solutions directly taken from knowledge management programmes that have been successfully adopted by other organisations. These solutions may not lead to an equivalent result if they do not meet the actual organisational needs. Chua and Lam (2005) analysed five cases of knowledge management failure and identified four main reasons for this: technology (infrastructure, tools and technology), culture (e.g. lack of trust, management commitment), content (including the structuring and relevance of the content of knowledge) and project management (including poor understanding of the knowledge requirements of users, rollout strategy and cost). In addition to these factors, barriers from a more individual level also have an influence, e.g. information pathologies which include individuals who belong to the not-invented here 
syndrome and hence reject ideas, or cling to weak ones to preserve self-esteem (Reichwald et al. 2010).

The lack of target in a knowledge management strategy is recognised as one of the critical factors mining the success of knowledge management and is one of the four factors identified by Chua and Lam (2005). Identifying the needs within the organisation prior to designing the activities and ensuring that they address these needs is imperative for the success of the knowledge management strategy to ensure users' knowledge requirements are incorporated.

The importance of developing a knowledge management strategy to address the needs of the organisation is also confirmed through other research studies. For example, Storey and Barnett (2000) describe two of the most important challenges related to the development of a successful knowledge management strategy as insufficiently specific business objectives and inadequate focus on one or two main priorities.

\subsection{Knowledge management strategies}

Various frameworks have been proposed in the literature in order to develop a knowledge management strategy. A common element across frameworks is the identification of a specific problem that the strategy for managing knowledge has to address. Figure 2 shows the frameworks proposed by Earl (2001) and Kamara et al. (2002), respectively. The first is a general framework that addresses the conceptual phase of knowledge management and is useful to define how knowledge management could be used to solve the identified problem (performance gap), whilst the second framework suggests the steps to follow from the identification of the problem to the definition of the knowledge management processes to implements. This last framework will be used in this paper to propose a knowledge management strategy suitable for the selected case study.

\subsection{Knowledge management in engineering}

In the engineering field, the interest in knowledge management issues is motivated by the growing amount of technical knowledge that a company has to capture, structure and organise to facilitate its retrieval and reuse during the development process. For example, in the case of variant design, up to $70 \%$ of information is reused from previous solutions (Khadilkar and Stauffer 1996). Furthermore, current trends in engineering design include the consideration of issues related to the later phases of product's lifecycle during the design process, resulting in the need to organise lifecycle knowledge to be accessible for engineering designers. The current flexibility of the job

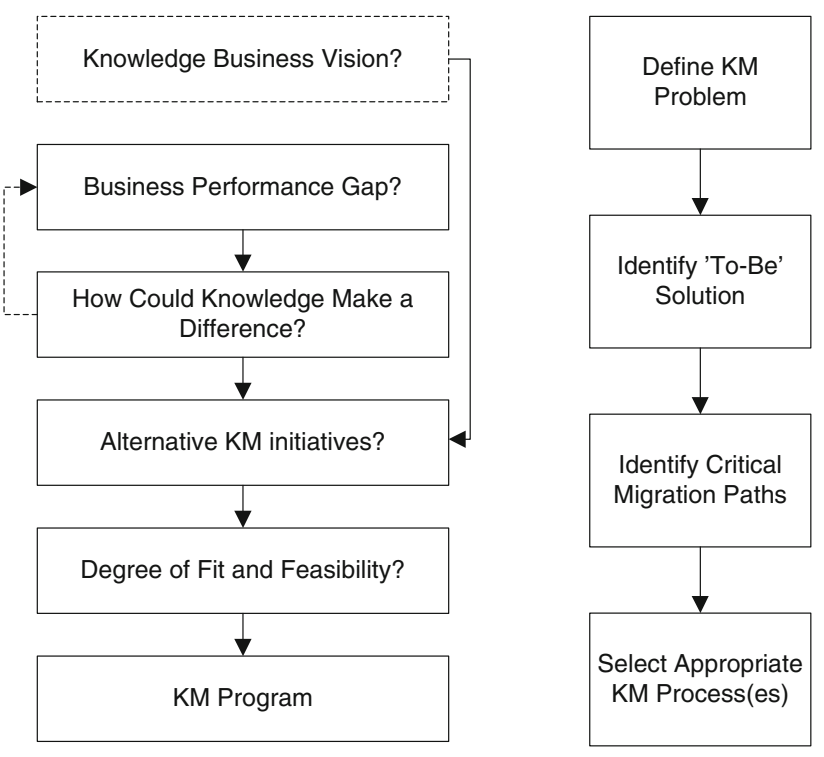

Fig. 2 Earl's (left) and Kamara et al.'s (right) frameworks for developing a knowledge management strategy

market reduces the probability for an engineer to have a lengthy career within any single company in particular in an Anglo-American context. This limits the reuse of personal expertise across projects and motivates companies to implement new approaches to facilitate the learning process and the reuse of past experience. Empirical studies have shown the difficulties for novices to formulate questions and define what they are looking for, hence highlighting their need for accessing knowledge in a simple way (Ahmed et al. 2003). Additional studies that focus on understanding knowledge needs include Heisig et al. (2010), who undertook surveys with design engineers and managers and identified rationale as the main reason for searching for design information.

The range of solutions extend from strategies focused on personalisation (Hansen et al. 1999; McMahon et al. 2004), aiming to support the sharing of information within the organisation by building personal networks amongst employees (Wenger 2000), to codification strategies that try to solve issues connected with knowledge management through information and communication technologies (McMahon et al. 2004). Selecting the appropriate approach is influenced by the type of organisation and the product.

A limited number of studies have been conducted in the engineering field to understand the knowledge arising during the service of products and how this can be reused during the lifecycle of a product or to support engineering designers during the design of similar products. Jagtap et al.'s (2007) research investigated the service phase from a design perspective through a case study from the aerospace industry. They identified the main requirement for 
service knowledge for engineering designers as: maintenance and failure data, reliability, service instructions and lifecycle costs. Additionally, the research identified the type of service information that engineering designers would like to access. Failure, operating and maintenance data together with design information, lifecycle costs and life of component were identified as the main types of information to be included in a service information system for the aerospace industry. The structuring of service information was found to be critical for the reuse of service information by engineering designers as quick retrieval of available documentation from different repositories is imperative in order to achieve systematic reuse of information from service. Jagtap and Johnson (2011) in a further empirical study with three engineers from the aerospace industry found that the current use of service knowledge in the design of new aeroengines was primarily related to information on deterioration. This could be the deterioration mechanism, the subsequent effects and causes.

Wong et al.'s case study (2007), also from the aerospace domain, resulted in a proposal for organising service knowledge and incorporating it into the design phase based upon a service-oriented architecture perspective. They proposed to integrate different knowledge repositories through defining ontology. Doultsinou et al. (2009) carried out a case study on smaller-scale products, namely vacuum pumps, and found that service knowledge can enhance design through improving: in-service reporting (records, etc.), access to operating conditions to where this pumps will be fitted and access to service facility descriptions.

\subsection{Engineering changes}

A type of knowledge that is particularly relevant in the engineering field is knowledge about engineering changes. Research on engineering change practice in industry has highlighted, through various case studies, that time spent on managing changes and time required for $\mathrm{EC}$ processes is significant if compared to the time needed for product development (Soderberg 1989; Lincke 1995; McIntosh 1995; Blackburn 1992). The time related to changes has a large impact on the cost of product development. Several studies have tried to quantify these costs, and despite differences from case to case, there is agreement amongst authors on the influence of EC on the total product development costs, i.e. in large development projects EC management consumes one-third to one half of engineering capacity (Soderberg 1989) and represent $20-50 \%$ of tool costs (Lincke 1995). According to McIntosh, ECs could affect between 70 and $80 \%$ of the final product's cost (McIntosh 1995). The cost of addressing changes also increases with the product's development process. Carter and Baker (1992) state that a design change after full-scale production may be around ten times as expensive as an equivalent design change identified at the conceptual stage of design and increases by an approximate factor of 10 as each phase of the product's lifecycle is surpassed (Terwiesch and Loch 1999). Ahmad et al. (2013) showed that information regarding the requirements, components, detailed design and function can assist designers in assessing the scope of redesign task following a change.

This literature review showed that studies from different research fields agree on the importance of knowledge transfer. Management and organisational research see it as a key factor for a company's success, whilst in engineering knowledge transfer is considered critical for product improvement.

The success of the knowledge management strategy is not in the amount of information that is stored into the repositories but in how the information is reused in order to achieve a predefined aim, which is dependent of the specific case (e.g. improve the design of a product and reduce the time to train new employees)

A number of the studies reviewed highlighted the need to consider the users' needs when capturing knowledge and to ensure adequate support for the access and reuse of this knowledge. These studies suggest that a knowledge management strategy has to be adapted to the specific context of use and targeted to a well-defined aim/problem.

Very few empirical studies of transferring knowledge from service knowledge were found, as also stated by Jagtap and Johnson (2011). Hence, the investigation of knowledge transfer in an engineering context is a field that requires further research. A better understanding of its mechanisms is crucial to develop a sound knowledge management system that fits a company's characteristics. Particularly, critical is the transfer and reuse of knowledge about changes they have a significant impact on development time and costs. For these reasons, this paper focuses on the analysis of content and mechanisms of knowledge transfer within an engineering context.

\section{Research design}

\subsection{Research methodology}

This research project consists of two stages, (1) a descriptive study and (2) a prescriptive study, and followed the approach suggested by Blessing and Chakrabarti (2009) for research into design (Fig. 3).

After having identified criteria for evaluating knowledge management through the literature survey, the research project focused upon the investigation of the knowledge relevant for service engineers and engineering designers and how this is captured and transferred. In this descriptive 
Fig. 3 Scheme illustrating design research methodology, where the focus of the research project is highlighted in red (colour figure online)

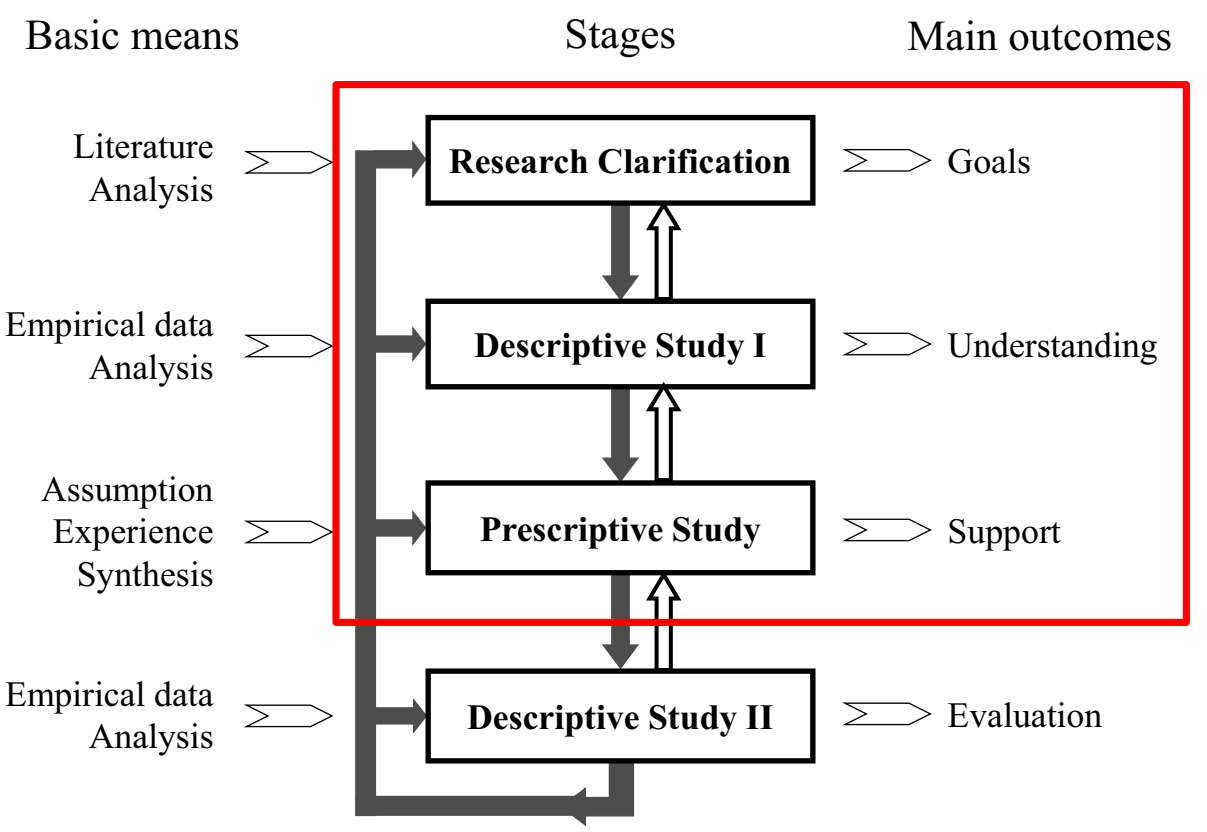

study, a case study approach was chosen in order to analyse knowledge management practises. The methodology selected to investigate the transfer and reuse of knowledge arising from the service phase of a complex engineering product is based upon case study research (Yin 1994). Case study research was selected as it allows conducting research in collaboration with industry and dealing with data collected in an industrial context, which was necessary for the research project.

The second part of the research (prescriptive study) was built upon the findings from the descriptive study and general frameworks for knowledge management, and developed guidelines to support the development and implementation of a knowledge management strategy aiming to facilitate the reuse of knowledge from the service phase.

\subsection{Descriptive study}

\subsubsection{Case selection}

The selected case study focused upon a complex business to business industry, specifically a supplier of drilling systems for the oil industry. The configuration of the drilling system is specific for each series of rigs (usually between two and four rigs are produced), so redesign or adaptation of the equipment and the assembly processes are required for each project. Each set of equipment has a number of characteristics that contribute to their complexity, which include the long lifecycle of the products (around 25 years) and the large number of interaction between the equipment.
The company supplying the drilling systems is involved throughout all of their lifecycle, first with responsibility for installation and commissioning of the drilling package, secondly providing training to the rig crews and finally supplying service and maintenance during the operation and service phase (partially through a 2-year warranty period, and the remainder through contracted services). Hence, knowledge covering the different phases of the lifecycle is available inside the company both as documentation and as experience of the employees working on the project.

As drilling systems are typically tailored for each order (i.e. customised equipment), the prototype and testing phase is limited compared with a serial product; hence, the transfer of experience between projects and reuse of knowledge from operation is essential to ensure that the equipment is designed correctly the first time, especially as the cost of downtime on an oil rig is very high. In contrast, a variant design industry (for example the aerospace industry) can more readily reuse the design, whereas in this case it is the knowledge and learning from problems that have occurred during operation and transferring this knowledge to the requirements for the design of the next set of equipment that is imperative in particular due to the high downtime cost. This knowledge is also relevant in variant design domains (Wong et al. 2007; Jagtap and Johnson 2011; Doultsinou et al. 2009).

\subsubsection{Data collection}

A total of 21 interviews with engineering designers and service engineers were carried out at the company 
headquarters in Norway and on a jack-up oil rig during its commissioning phase, see Table 1 . As the aim was to better understand the transfer of knowledge from the service phase to the engineering design phase, the participants were selected to represent engineers from the operations (service engineers) and those working with the design of the equipment (design division) (see Table 1). The interviews were semi-structured, and the questions asked were related to: communication, knowledge requirements of the participants and the reuse of experience across projects or service cases. An interview guide was established with questions formulated within all of these categories, to investigate how knowledge is currently transferred between these service and design phases and to gain knowledge of the knowledge requirements from both phases. Example questions included: Which knowledge of the operation of the machines is useful during the design phase? (question for the engineering designers) or Which knowledge of the design of the machines is useful during the service phase? (question for the service engineers). The questions were standardised, and some were specific for the service or the engineering design division, with the majority of questions being common to both. The semi-structured nature of the interview allowed the participants to expand on the answers, whilst ensuring all interviews were conducted and questions were asked consistently across all interviews.

All of the interviews were audio-recorded and lasted between 20 and $60 \mathrm{~min}$; the interviews that were carried out on the rig were shorter due to the limited time available of the service engineers.

Table 1 Participants interviewed

\begin{tabular}{llllll}
\hline Location & \multicolumn{2}{l}{ Engineering designers } & & \multicolumn{2}{l}{ Service engineers } \\
\cline { 2 - 3 } & Headquarters & Rig & & Headquarters & Rig \\
\hline No. of participants & 10 & 2 & & 7 & 2 \\
\hline
\end{tabular}

\subsubsection{Data analysis}

The interviews were transcribed and segmented in meaningful instances, resulting in 4,750 segments. The transcripts were coded with a coding scheme developed from the literature on service knowledge, knowledge management and organisational learning and were completed following a bottom-up approach. The scheme included different categories, each embracing codes and subcodes. The subcodes within any of the codes are mutually exclusive. An overview of the categories and the main codes is shown in Table 2. A sample of the collected data and of how they were analysed using the coding scheme is presented in Table 3.

In addition to coding the data using the knowledge transfer mechanism, all the instances were coded against two additional binary codes: wanted and missing knowledge; these statements were separated from statements describing the current situation.

In the final coding scheme, there was also a need to identify the types of knowledge that was relevant for service engineers and engineering designers. Hence, for this part of the coding scheme initially included four subcodes: product, process, issues and function (Ahmed 2005). This was expanded through the addition of more subcodes following a bottom-up approach to cover the entire span of knowledge emerging from the interviews and to ensure that there were no missing codes. Hence, the final coding scheme consisted of: the coding schemes for knowledge transfer (Table 2), the codes for wanted, missing knowledge and the final subcodes describing the types of knowledge (as described below):

- Product including its design and its functionalities.

- Process and procedures related to the workflow followed to accomplish a task.

- Changes, issues and improvements associated with variations to the original design of the product, motivated by the correction of a design flaw or the need for improvement.

Table 2 Coding scheme for knowledge transfer

\begin{tabular}{llll}
\hline Categories & Codes (subcodes) & Definition & Literature \\
\hline $\begin{array}{l}\text { Knowledge } \\
\text { characteristics }\end{array}$ & $\begin{array}{c}\text { Types of knowledge } \\
\text { (product, process, etc.) }\end{array}$ & The object of knowledge & Jagtap et al. (2007), Ahmed \\
$\begin{array}{l}\text { Knowledge } \\
\text { transfer }\end{array}$ & $\begin{array}{l}\text { Sender/receiver } \\
\text { Initiation mechanisms (push, } \\
\text { pull, fixed) }\end{array}$ & $\begin{array}{c}\text { Parties involved in knowledge transfer } \\
\text { Transfer pulled by the receiver, pushed by the sender or } \\
\text { occurring through planned activities. }\end{array}$ & $\begin{array}{c}\text { Lin et al. (2005). } \\
\text { McMahon et al. (2004) }\end{array}$ \\
& $\begin{array}{c}\text { Type of capture (personal, } \\
\text { codified) }\end{array}$ & $\begin{array}{c}\text { Transfer in codified ways or relying on people } \\
\text { Context (within project, } \\
\text { across projects) }\end{array}$ & $\begin{array}{c}\text { McMahon et al. (2004) } \\
\text { Bottom-up approach }\end{array}$ \\
\end{tabular}


Table 3 Example of collected data and their analysis

\begin{tabular}{|c|c|c|c|c|c|c|}
\hline \multicolumn{2}{|c|}{ Knowledge need } & \multirow{2}{*}{$\begin{array}{l}\text { Knowledge } \\
\text { type: (object) }\end{array}$} & \multicolumn{4}{|c|}{ Knowledge Transfer } \\
\hline Missing & Wanted & & $\begin{array}{l}\text { Type of } \\
\text { capture }\end{array}$ & Sender & Receiver & Mechanism \\
\hline
\end{tabular}

Q Do you receive reports of service interventions?

A No I would say not, but they ARE available. Eehm, there are some SPS sites, that we can jump into, and try to find out. But we don't do that

A Where we have problems, we might do that directly ourselves, but we usually go through service, senior service. The senior service group, if we need to have some experience transfer, from a special rig

Q When does the senior service group contact you?

A If they have a problem that they either do not have resources for handling or technical experience, or if they sort of getting into design issues, then they contact us

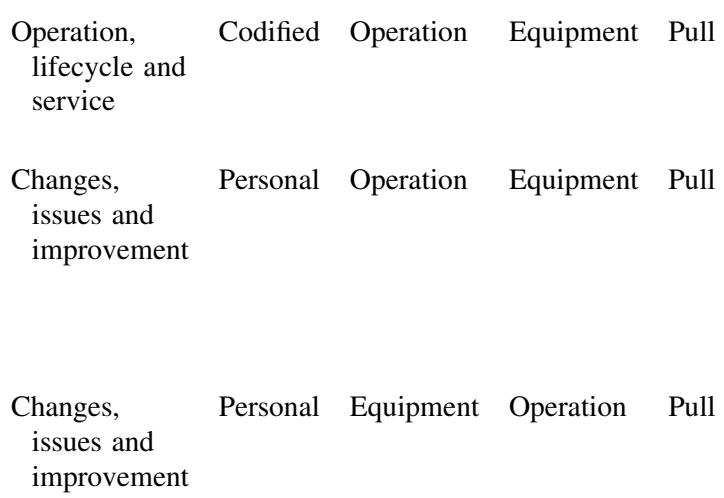

- Project following the development of the drilling system for a specific rig throughout its lifecycle, including set-up of requirements, reviews of the different phases, interaction with client and suppliers, time schedule, results from test, etc. People and organisation: related to the organisational structure and the awareness of who knows what.

- Operation and lifecycle including knowledge on a drilling system after the design phase was completed: its use, maintenance and service.

- Function representing the task a particular component or assembly has to fulfil.

- Domain knowledge including background knowledge on electronics, hydraulics, computer programming, oil industry, drilling methods, etc.

After investigated the types of relevant knowledge for service engineers and engineering designers, the analysis focused upon the knowledge transfer mechanisms and how this can be related to the two groups involved and their knowledge characteristics.

A portion of the transcripts was coded by two researchers, and a coder-reliability check was conducted. The Cohen kappa from the coder-reliability check was 0.91 and considered excellent; all disagreements were checked and an agreement reached.

\subsection{Prescriptive study}

The findings from the descriptive study where service knowledge and its transfer within and across lifecycle phases were investigated were applied to the framework proposed by Kamara et al. (2002) in order to develop a knowledge management strategy to support the reuse service knowledge.

\section{Results from the case study}

\subsection{Characteristics of knowledge arising} from the service phase

\subsubsection{Types of knowledge}

The types of knowledge relevant for engineering designers and service engineers, respectively, were analysed, and the results are shown in Fig. 4. The results indicate that both groups were interested in changes, issues and improvements. Additionally, knowledge that was particularly relevant for engineering designers was related to product (25\% of the instances), whilst service engineers were interested in knowledge about projects and how these evolved over time.

The interviews also investigated the types of knowledge engineering designers, and service engineers would have liked to have access to and which knowledge was described in negative terms, as either not available or not used. Instances describing these two conditions were identified using the auxiliary codes of wanted and missing knowledge. Figures 5 and 6 illustrate these results.

Different trends were observed for the service engineers in comparison with the engineering designers. The service engineers desired more knowledge about the project to be available, whilst the engineering designers perceived 
Fig. 4 Distribution of the types of knowledge described by engineering designers and service engineers during the interviews. The values are percentages, calculated on a total of 311 instances for engineering designers and 127 for service engineers
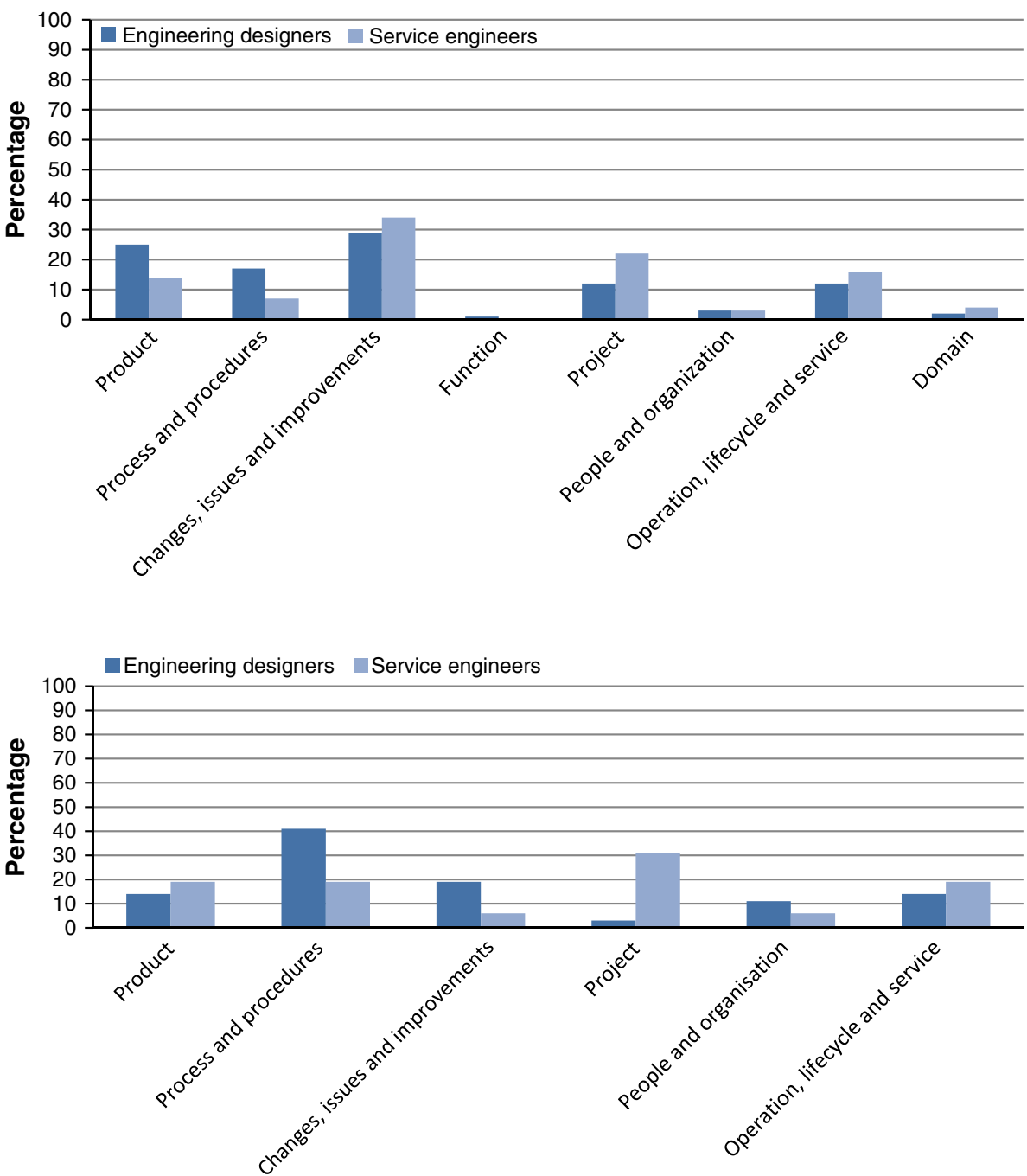

Fig. 5 Knowledge desired by engineering designers and service engineers. The values are percentages, calculated on a total of 37 instances for engineering designers and 16 for service engineers
Fig. 6 Knowledge perceived as missing for service engineers. The values are percentages, calculated from a total of 45 instances (as there were only two instances for engineering designers, these are not presented)

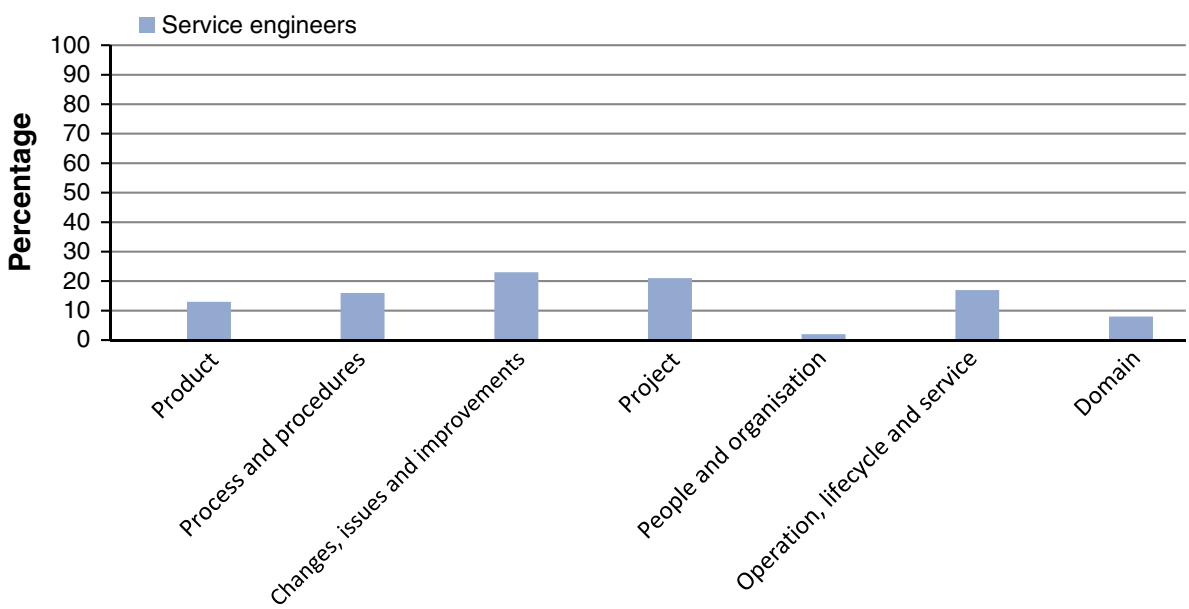

process knowledge as the type of knowledge that they would like to have access to. Differences between the two groups were particularly visible through the analysis of the types of knowledge that were perceived as missing. Engineering designers mentioned the lack of available knowledge only twice, whilst service engineers mentioned 
Table 4 Percentages of instances describing knowledge captured through personalisation and codification strategies; the numbers of instances are shown in parenthesis

\begin{tabular}{|c|c|c|c|c|}
\hline & \multicolumn{2}{|c|}{ Service engineers } & \multicolumn{2}{|c|}{ Engineering designers } \\
\hline & Codification & Personalisation & Codification & Personalisation \\
\hline Changes, issues and improvements & $52 \%(17)$ & $48 \%(16)$ & $63 \%(44)$ & $37 \%(26)$ \\
\hline Domain knowledge & $0 \%(0)$ & $100 \%(4)$ & $50 \%(1)$ & $50 \%(1)$ \\
\hline Operation, lifecycle and service & $72 \%(13)$ & $28 \%(5)$ & $76 \%(13)$ & $24 \%$ \\
\hline People and organisation & $100 \%(1)$ & $0 \%(0)$ & $67 \%(4)$ & $33 \%(2)$ \\
\hline Process and procedures & $80 \%(4)$ & $20 \%$ & $74 \%(14)$ & $26 \%(5)$ \\
\hline Product & $46 \%(6)$ & $54 \%(7)$ & $41 \%(18)$ & $59 \%(27)$ \\
\hline Project & $77 \%(17)$ & $23 \%(5)$ & $57 \%(13)$ & $43 \%(10)$ \\
\hline Total $(\%)$ & $60 \%(58)$ & $40 \%(38)$ & $59 \%(108)$ & $41 \%(75)$ \\
\hline
\end{tabular}

The percentages refer to the number of instances describing each type of knowledge (the rows) from service engineers and engineering designers, respectively

missing knowledge in 45 instances, suggesting that service engineers had a much greater need for additional knowledge. This perception of missing knowledge from service engineers was not linked to any specific type of knowledge but included knowledge about changes, project, operation, procedures, etc.

\subsection{Knowledge transfer}

within and across organisational boundaries

\subsubsection{Strategies for capturing and transferring knowledge}

The interviews from the supplier of drilling equipment were analysed to investigate how knowledge was currently captured: these distinguished between knowledge captured into repositories and hence transferred through codification strategies, and knowledge internal to the individuals and consequently transferred through personalisation strategies such as informal communication amongst colleagues or meetings. Whilst knowledge transferred through personalisation always results in new knowledge available for the receiver, when codification strategies are adopted, knowledge is captured into documentation but is not necessarily reused.

The adoption of personalisation or codification strategies for capturing and transferring knowledge was investigated in relation to: (1) the types of knowledge (already described) and (2) the two groups participating in the interviews, service engineers and engineering designers. The results summarised in Table 4 show that the distribution of instances describing personalisation and codification strategies was comparable for the two groups, with approximately $60 \%$ of the knowledge captured into documentation. The trends for each single type of knowledge were also comparable. The only types of knowledge with dissimilar distributions of strategies for knowledge transfer were domain knowledge and knowledge about people and organisation. However, given that only three instances of domain knowledge were recorded, this is not statistically significant and hence inconclusive without further investigation.

Table 4 shows the types of knowledge whose transfer still relied predominantly upon personalisation strategies, i.e. domain knowledge, product and changes, issues and improvements. From these types of knowledge, knowledge of the product and changes, issues and improvements were found from the analysis as the most relevant for service engineers and engineering designers (see Sect. 5.1). The mechanisms adopted for transferring knowledge are further investigated in the following sessions.

\subsubsection{Transfer mechanisms within and across phases}

Table 5 shows the results of the analysis of knowledge transfer mechanisms between service engineers and engineering designers. A sender-receiver framework and the transfer mechanisms: push, pull or symmetric transfer were used to analyse the data. This can be read across the table as the senders, for example, the first row shows the engineering designers sending either to other engineering designers or across phases to the service engineers, whereas the columns of the tables show the breakdown of information received by either the engineering designers or the service engineers. The transfer within the design phase (i.e. engineering designers as the senders) tended to be symmetric, occurring through meetings or personal contact, whilst transfer across phases and within service was mainly asymmetric: pushed when transfer occurred from service to design or within service and pulled from design to service. Service engineers tended to actively make knowledge available by pushing it towards other service engineers and engineering designers, whilst at the same time they needed 
Table 5 Knowledge transfer between service engineers and engineering designers and its mechanisms

\begin{tabular}{|c|c|c|c|}
\hline & \multicolumn{2}{|l|}{ Receiver } & \multirow{2}{*}{$\begin{array}{l}\text { Transfer } \\
\text { mechanism }\end{array}$} \\
\hline & $\begin{array}{l}\text { Engineering } \\
\text { designers }\end{array}$ & $\begin{array}{l}\text { Service } \\
\text { engineers }\end{array}$ & \\
\hline \multicolumn{4}{|l|}{ Sender } \\
\hline \multirow{6}{*}{$\begin{array}{c}\text { Engineering } \\
\text { designers }\end{array}$} & 4 & 19 & Push \\
\hline & 3 & 25 & Pull \\
\hline & 6 & 0 & Fixed \\
\hline & 7 & 3 & $\begin{array}{r}\text { Personal } \\
\text { contact }\end{array}$ \\
\hline & 4 & 0 & Supervision \\
\hline & $24 \%$ & $47 \%$ & Subtotal \\
\hline \multirow{5}{*}{$\begin{array}{l}\text { Service } \\
\text { engineers }\end{array}$} & 44 & 25 & Push \\
\hline & 21 & 11 & Pull \\
\hline & 6 & 8 & Fixed \\
\hline & 6 & 8 & $\begin{array}{r}\text { Personal } \\
\text { contact }\end{array}$ \\
\hline & $76 \%$ & $53 \%$ & Subtotal \\
\hline Total & $\begin{array}{r}100 \%(72 \\
\text { instance) }\end{array}$ & $\begin{array}{c}100 \% \text { (36 } \\
\text { instances) }\end{array}$ & \\
\hline
\end{tabular}

to pull knowledge from engineering designers. As shown in Table 5, $44 \%$ of knowledge and information received by designers was pushed from operation; however, information transferred through codification by storing documentation into the company's repositories was not necessarily reused by the engineering designers.

One of the engineering designers that participated in the interviews described the way he accessed information from the service phase as:

I cover the position of the department manager and use my people working with the technical stuff. If I need someone competent for a piece of equipment, the product responsible is the best man because every report goes back to him. If there is some problem if they use the $\mathrm{CCN}$, the mail or something it will go through him as he is the specialist on the equipment.

This tendency of relying on people (i.e. the product responsible) for accessing information about product as well as changes, issues and improvements led to overloading experienced designers with new tasks; as together with completing their job, they also had to support other positions by providing their personal knowledge, also observed by Jensen and Ahmed-Kristensen (2009).

Service engineers heavily relied on personalisation strategies whilst collecting or transferring information from service. For instance, a service engineer described how he dealt with information about issues arising during service, in the following terms:
That varies, it is not done in a systematic way... so depends on... sometimes just a telephone call or whatever if you really know exactly who is dealing with it and so on... But sometimes you just don't bother... if it isn't important... when we are fixing things in our end of the company we of course go back to the product responsible and get an approval down and we correct some drawings.

Statements like the ones reported above stressed the importance of the role played by the product responsible (engineering designers with responsibility for a particular product), in order to support the transfer of knowledge across phases of a product's lifecycle. A qualitative analysis of the interviews showed that senior positions, both amongst engineering designers (i.e. product responsible) and service engineers (i.e. senior service engineers), acted as knowledge brokers, facilitating the transfer of both personal knowledge and information that was captured into documentation. A knowledge broker is described in the literature as an intermediary who facilitates the knowledge transfer process providing links, pointing to sources or directly supplying knowledge (Hargadon 1998); brokering practices include crossing organisational boundaries, translating and interpreting available knowledge according to the needs of the receiver and support the transfer of knowledge across units in the organisation (Pawlowski and Robey 2004). In the case study analysed, one department tended to contact a broker from the other department rather than to look for available documentation; this resulted in the broker overloaded by work in order to supply information in form of personal communication, ad hoc reports created to satisfy the receiver needs or already available documentation.

When knowledge was transferred through codification strategies, a third element was part of the communication flow, together with the sender and the receiver: the knowledge repositories (see Fig. 7). The sender pushes information into repositories; the same information can be pulled by the receiver or pushed to him in the form of notifications, alerts, etc. In this case, the knowledge broker could support the transfer process by pointing to available documentation from the repositories or requesting further information from the sender.

\subsubsection{Knowledge transfer within service}

The mechanisms characterising knowledge transfer amongst service engineers were analysed in relation to the type of knowledge transferred and the strategy adopted. As shown in Table 6, when knowledge was transferred through codification strategies, it was primarily pushed into repositories, in the form of documentation about changes, 
Fig. 7 Knowledge transfer throughout personalisation and codification

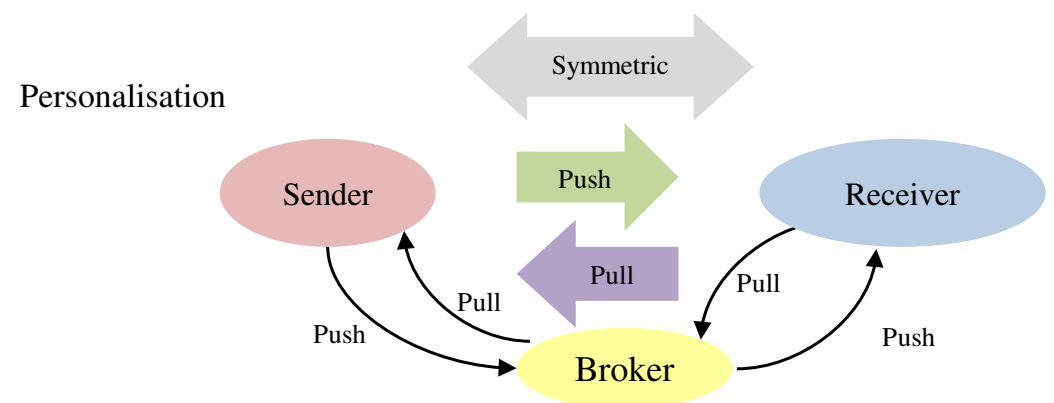

Codification
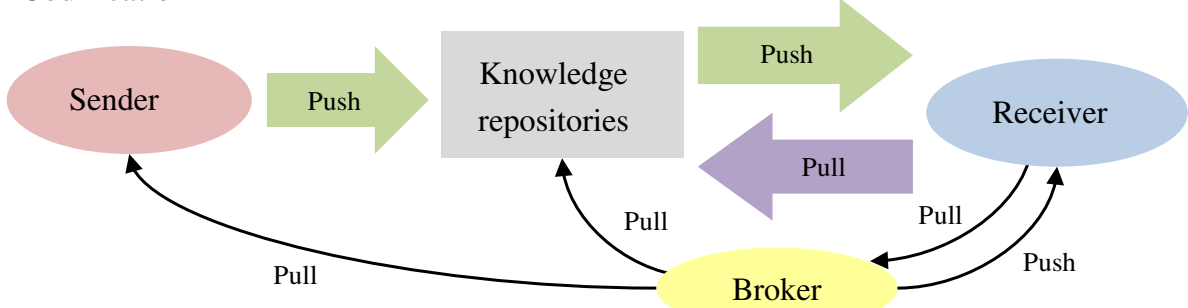

issues and improvements; however, none of the service engineers interviewed actively retrieved (i.e. pulled) this documentation from the repositories. Whilst service engineers actively searched for codified information about a project and the operation of the equipment, they only accessed information about changes through personalisation strategies.

A similar pattern emerged from the analysis of the mechanisms for transferring knowledge at fixed stages of a project. The documentation generated at predefined stages focused upon the progressions of a project, the development of a product or fixed gates of the lifecycle; however, it did not include systematic reviews of changes, issues and improvements. This type of knowledge was transferred through personal communication amongst service engineers, such as in meetings.

These results suggest a mismatch between information about changes that was captured into repositories and that needed by service engineers. Although information on changes was extensively captured into documentation (33\% of the instances describing knowledge captured into documentation regarded changes), service engineers preferred to access this type of knowledge through personalisation strategies.

\subsubsection{Knowledge transfer from service engineers to engineering designers}

Finally, the knowledge transfer from operation to design was specifically analysed in relation to its content and the initiation mode; the results are illustrated in Table 7. The main codified knowledge that was transferred across organisational boundaries was about changes, issues and improvements; this was mainly pushed by service engineers (more than $50 \%$ of total instances describing transfer of codified knowledge) and, to a lesser degree, pulled by engineering designers. Personalised knowledge was equally pushed and pulled from operation to design. Knowledge pushed to engineering designers by service engineers largely concerned changes, whereas engineering designers also pulled knowledge about operation and, to a lesser extent, project and product. From this analysis, changes, issues and improvements arising during operation emerged as the main knowledge transferred to engineering designers, confirming the results from the investigation of the types of knowledge relevant for the two groups. However, it is evident that no single strategy for transferring this type of knowledge was followed as transfer occurred both through codification and personalisation.

The interviews also indicated that knowledge transfer between service engineers and engineering designers was perceived as an issue by service engineers, who experienced recurrent problems. They would have preferred a greater involvement in the design process in order to ensure that their experience from the field was taken into account whilst designing new products, whereas systematic transfer of knowledge from the service phase was less relevant from the perspective of engineering designers, who did not perceive a systematic reuse of inputs from service, whilst designing a product as their main priority. They expected service engineers to make them aware of issues arising during service by being the drivers of the knowledge flow. This explains why most of the information was pushed from operation to design.

The limited interest of the designers for knowledge arising throughout the lifecycle of a product may be linked 
Table 6 Knowledge transferred within service

\begin{tabular}{|c|c|c|}
\hline & $\begin{array}{l}\text { Codified } \\
\text { (43 instances) }\end{array}$ & $\begin{array}{l}\text { Personal } \\
\text { (24 instances) }\end{array}$ \\
\hline Push & 63 & 25 \\
\hline Changes, issues and improvements & 33 & 21 \\
\hline Operation, lifecycle and service & 12 & 4 \\
\hline Process and procedures & 5 & 0 \\
\hline Product & 2 & 0 \\
\hline Project & 12 & 0 \\
\hline Pull & 21 & 42 \\
\hline Changes, issues and improvements & 0 & 13 \\
\hline Domain knowledge & 0 & 4 \\
\hline Operation, lifecycle and service & 9 & 0 \\
\hline Product & 2 & 13 \\
\hline Project & 9 & 13 \\
\hline Fixed & 16 & 8 \\
\hline Changes, issues and improvements & 0 & 8 \\
\hline Operation, lifecycle and service & 5 & 0 \\
\hline Product & 5 & 0 \\
\hline Project & 7 & 0 \\
\hline Personal contact & 0 & 25 \\
\hline Changes, issues and improvements & 0 & 13 \\
\hline Domain knowledge & 0 & 4 \\
\hline Operation, lifecycle and service & 0 & 4 \\
\hline Process and procedures & 0 & 4 \\
\hline Total & 100 & 100 \\
\hline
\end{tabular}

to the characteristics of the oil industry, which is still very conservative: the provision of service and maintenance is still seen as a source of profit for the supplier of drilling equipment, as guarantees of the performances are not included in the contract with the client. Hence, there is not a strong motivation for focusing upon product lifecycle issues, which is the case when product-service systems are supplied, e.g. in the aerospace industry.

The results also highlighted issues with the suitability of knowledge repositories for transferring knowledge across departments: although service engineers made service information available in a codified manner, designers tended to retrieve information from service by pulling it through personalisation, as stated by an engineering designers who were interviewed.

During project phases, you start to know people, you get in contact with people, so you are, after some years, in the company, you are definitely able to ask the questions to the right people, if you want to. So it is actually easier for us to be able to ask people.

Additionally, as suggested by Argote's framework (Pawlowski and Robey 2004), the interviews described knowledge transfer occurring by moving knowledge
Table 7 Knowledge transferred from service to design

\begin{tabular}{llc}
\hline Sender: service engineers & \multicolumn{2}{l}{$\begin{array}{l}\text { Receiver: engineering } \\
\text { designers }\end{array}$} \\
\cline { 2 - 3 } \cline { 2 - 3 } & $\begin{array}{l}\text { Codified \% } \\
(23 \text { instances })\end{array}$ & $\begin{array}{c}\text { Personal } \% \\
(27 \text { instances })\end{array}$ \\
\hline Push & 70 & 41 \\
Changes, issues and improvements & 52 & 37 \\
Project & 9 & 4 \\
People and organisation & 4 & 0 \\
Operation, lifecycle and service & 4 & 0 \\
Pull & 22 & 37 \\
Product & 0 & 4 \\
Changes, issues and improvements & 13 & 15 \\
Project & 0 & 7 \\
Operation, lifecycle and service & 9 & 11 \\
Fixed & 9 & 7 \\
Changes, issues and improvements & 0 & 4 \\
Operation, lifecycle and service & 9 & 4 \\
Personal contact & 0 & 11 \\
Product & 0 & 4 \\
Changes, issues and improvements & 0 & 100 \\
Total & & \\
\hline
\end{tabular}

reservoirs. Moving personnel across departments had been the focus of an employee development project implemented within the company before the interviews were carried out. The project, although successful, was interrupted due to the exponential development of the oil business that impeded the temporary allocation of engineering designers to other departments. Nonetheless, the benefits of that programme were still visible at the company as designers who participated in the programme had a better vision of the lifecycle of the equipment and formed a network of contacts in the operation department which was still active.

Although the rotation programme was no longer active, the temporary moving of personnel from the design department, particularly software developers, was still common in order to support the most critical parts of the commissioning phase, which also had the positive effect of facilitating the communication across departments.

\subsection{Implication for a knowledge management system}

\subsubsection{Knowledge to capture}

The results of the analysis of the interviews showed the types of knowledge arising from the later phases of the lifecycle of the equipment, particularly from the service phase, that were relevant for service engineers and engineering designers. These findings need to be considered 
whilst developing a knowledge management strategy to reuse service knowledge, as implementing a strategy that focuses upon knowledge that is not relevant for the expected users would result in a waste of time and resources.

\subsubsection{Knowledge relevant for the service phase}

The knowledge emerging from the service phase that is relevant for service engineers regards mainly:

- Changes, issues and improvements that occurred in equipment with characteristics similar to the one to service.

- Project knowledge, describing the history of a rig, in particular the progression of the works during the installation and commissioning phases.

- Operation, lifecycle and service describing the working conditions of a piece of equipment, its maintenance, performances, etc.

When the reuse of knowledge occurred within the service phase, the reuse process was facilitated by the fact that the service engineers generating knowledge and the ones reusing it share the same background and perspective towards the knowledge object; hence, no translation process is required in order to support the transfer. As service engineers acquired the same type of implicit and tacit knowledge during their daily work, when knowledge from a service case is captured into documentation there is a lesser need to describe the context of the information in order to facilitate its reuse compared to when knowledge is expected to be transferred across organisational boundaries, e.g. from service to engineering designers.

\subsubsection{Knowledge relevant across phases of the lifecycle}

The knowledge related to the service phase that was also relevant for engineering designers included:

- Knowledge about changes, issues and improvements and product,

- Procedures for developing a product taking into account the reuse of knowledge from past cases.

Hence, knowledge of changes, issues and improvements arising during the service phase emerged as of common interest to service engineers and engineering designers; if this knowledge was structured considering the needs of the two groups, it could be used as a boundary object able to facilitate communication between engineers involved in different phases of the product lifecycle. However, the different perspectives of the two departments were reflected in the nature of documentation. Service documentation aimed to capture dynamic knowledge of value mainly at the moment when it was issued and available in form of service reports or status descriptions; design documentation on the other hand represented more stable knowledge entailed in drawings, valid throughout the lifecycle of a product and relatively easy to reuse across projects.

Comparing the findings from this case study on transfer of knowledge from the service phase of customised equipment, with the types of service knowledge relevant for engineering designers in other industries, namely variant design of complex machinery (Jagtap et al. 2007), the information on failures, maintenance and lifecycle is common for both variant and customised designs whilst the importance of knowledge about current and past projects was only seen in the case of customised equipment. Other comparisons between the aerospace industry (variant design) and customised equipment (oil drilling equipment) point to differences in the handling of service cases, with variant design more readily reusing design, and customised design focusing upon reusing the process (Vianello et al. 2010).

\subsubsection{Knowledge management}

The analysis of the case study indicated that the strategies adopted for transferring knowledge were not coherent, as knowledge transfer mechanisms were not defined at organisational level and were dependent on the specific situation. Within the service phase, knowledge and information were transferred through a mix of codified and personal approaches, whereas the transfer of knowledge and information between departments involved in different phases of the lifecycle occurred mainly through personal approaches and through the senior employees, e.g. the product responsible, acting as knowledge brokers. Although codified information was pushed by service engineers into repositories accessible to engineering designers, it was rarely reused.

The combination of personal and codified approaches towards knowledge transfer that characterised the service practice was not consistent with the management's preference for codification strategies. This preference for codification strategies was motivated by the product's long lifecycle, the high turnover and internal mobility of the employees compared to the length of the lifecycle making strategies based on personalisation hazardous.

The interviews identified various reasons explaining this mismatch between expectations of the management and practice, including:

- No comprehensive knowledge management strategy available at organisational level.

- Gap between the information stored and the information needed, particularly when information was 
expected to be reused across organisational borders (e.g. across division or business unit).

The findings from the analysis of the case study are consistent with those described in the literature for other industrial cases and confirm issues such as the lack of knowledge sharing across business units, for example, Wenger et al. (2002) describe the case from the automotive industry where Chrysler (the Chrysler unit of Daimler Chrysler) moved to a product-based organisation to facilitate better knowledge sharing between the engineering and services units of the product development process, but subsequently found the need to set up communities of practice to facilitate transfer of experience across the new business units. Additionally, the gap between the information stored and the information needed confirms the common issue of poor identification of the main objective of a knowledge management system that was highlighted by Storey and Barnett (2000) where little focus is placed on the user knowledge needs. For example, in this case, the need to retrieve knowledge in different ways for the different user groups, with service engineers preferring to access knowledge at the equipment level and engineering designers at the component level of the product.

\section{Development of a suitable knowledge management strategy}

The analysis of the knowledge transfer practices at the supplier of drilling equipment suggested factors that needed to be taken into consideration when developing a knowledge management strategy to support knowledge transfer through codification. In the case taken into consideration, the importance of transferring knowledge through codification strategies appeared more evident than in other contexts, due to the long period of time when knowledge was generated and the variety of actors involved in the process of knowledge creation.

The steps for selecting a knowledge management strategy suggested by Kamara et al.'s framework, which have been summarised in Fig. 3, were followed in order to propose a suitable strategy and are described in detail in the following sections.

\subsection{Problem identification}

The first step of the framework identifies the problems to tackle. The analysis of the case of the supplier of drilling equipment showed that the type of knowledge arising from the service phase that was most relevant for both service engineers and engineering designers was knowledge about changes, issues and improvements; however, still no specific strategy was developed in order to facilitate the reuse of this type of information. Knowledge management strategies based upon codification were available at the collaborating company in order to systematically capture knowledge arising throughout the different phases of the lifecycle of drilling equipment; however, the preferred way to transfer this knowledge across members of the organisation was based upon personal approaches.

The consequences of the lack of knowledge management strategy supporting a systematic reuse of information from service included:

- Recurrent issues were not addressed in a consistent way as experience from past cases was not systematically reused during a service intervention.

- Support of senior positions was required in order to supervise service interventions and validate the selected solution through personal experience.

- Service engineers informed engineering designers of problems arising from service through personalisation strategies, even when documentation was available, as engineering designers had difficulties obtaining relevant information from available documentation.

Various areas of improvement, related to the phase of the lifecycle where knowledge was expected to be reused, emerged from the analysis of the case study.

In the service phase, knowledge supporting service engineers whilst servicing the drilling equipment were not easily available from the repositories in a form that can be reused for new cases, particularly:

- Experience from previous cases was difficult to reuse during a new service intervention when the person had not been involved in the past case. Documentation reflected the style and perception of the service engineer generating it; hence, it was not always easy to obtain relevant information from available documentation, and similarities across cases were hard to assess (as reports were not created for their reuse)

- It was difficult to obtain an overview of a project overtime, to understand what was done and tasks that were still incomplete, etc.

In the design phase, engineering designers incorporated experience from service into the design of new products through their personal knowledge, and they expected service engineers to contact them (e.g. the relevant product responsible) in case of major problems. Hence, rarely referred to available documentation, which was perceived as a time-consuming activity, with challenges related to:

- Relevance of the information;

- Reliability-validation of the likely cause of failure was often missing; 
- Completeness;

- Fragmentation-information about a service case was often scattered across repositories.

\subsection{Desired state}

A framework to show the desired transfer of knowledge has been proposed in Fig. 8. From the case study, the main type of knowledge, whose reuse should be facilitated both within the service phase and across phases of the equipment lifecycle, is knowledge about changes, issues and improvements. A systematic reuse of this type of knowledge is beneficial in two dimensions:

- During the development phase, in order to improve the design of the next generation of products by avoiding issues already detected in previous products and evaluating suggestions for improvement.

- During the service phase, in order to provide faster and more consistent service interventions through the reuse of:

- Procedural knowledge: resulting in more consistency in the trouble shooting process and in the way projects are managed. This is essentially knowledge of the process if undertaking a service inquiry from diagnostics, analysis, abstraction and synthesis that can be reused for faster diagnosis by other service engineers and for supplying context to engineering designers.

- Declarative knowledge: providing service engineers with solutions implemented in previous similar cases.

Due to the characteristics of the oil industry, such as high internal mobility and high turnover of employees, the preferred way of transferring knowledge is through codification strategies.

\subsection{Identification of migration paths}

Once the objectives of the knowledge management strategy are defined, the paths to follow to meet these objectives need to be delineated.

In order to facilitate the reuse of documentation,

- Each service case needs to be indexed against the product and component it refers to, allowing engineering designers and service engineers to access the information at different levels of detail.

- The different phases of a service case should be documented in separate sections, with a clear structure, i.e.:

- Problem description,

- Trouble shooting,

- Root cause,

- Solution.

The interviews identified information overload as a major barrier for reusing knowledge, as can also be seen in the literature (Wallace et al. 2005). Retrieving and reviewing each document from past service interventions, which could be relevant for the current case, is a timeconsuming activity and does not always bring the desired result. The personal experience of the receiver is crucial to assess similarity between cases and understand how information from a past case could be reused. This problem is addressed in various research fields, for instance research on case-based reasoning (CBR) proposes a four-stage process that aims to support learning from past cases (Aamodt and Plaza 1994). These stages are as follows:

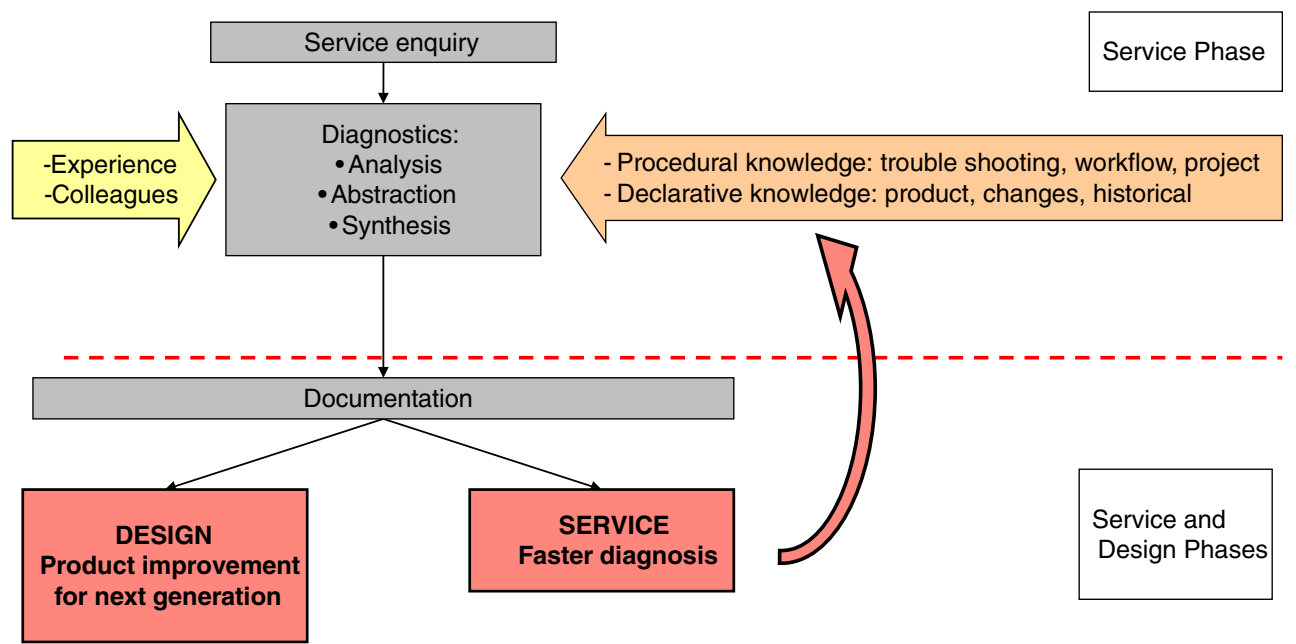

Fig. 8 The desired state 
- Retrieve,

- Reuse,

- Revise,

- Retain.

The last two stages are particularly important when developing a knowledge management strategy, as they focus upon how to capture and store knowledge arising from a new case. In the context of engineering design, an example from the aerospace industry refers to CBR systems as having the goals: to capture and provide access to specific design cases which can then become shared experienced; provide support for less experienced designers (in the case described in this paper, these would be for the less experienced service personnel for faster diagnosis see Fig. 8) to learn from the experience of others; and provision of support to adapt prior design knowledge to a new set of design requirements, this would be the case in the oil industry where designs are adapted and hence not so readily reuse; hence, the focus is on reusing procedural knowledge (Leake, 2001). Research in case-based reasoning indicates that knowledge from new cases needs to be integrated it into existing documentation, revised and retained in the form of new knowledge. This concept has been taken into account during the identification of the migration paths by introducing an "analysis" step that precedes the retrieval and reuse of documentation. The analysis step leads to the distinction between processed information (after analysis) and non-processed information (before analysis).

Non-processed information includes all the documents that were generated in relation to a case in order to address specific needs, e.g. service requests, spare part orders, service reports, repair methods. This type of information is strictly related to the specific case, the time when it has been generated and the context it refers to. For those users without prior awareness of the nature of the case and its context, difficulty arises in:

- Searching for relevant documentation;

- Obtaining a sufficient overview of the context of the original case, that allowed the comparison of cases and assessing relevance;

- Extracting the information needed from this type of documentation.

Processed information refers to information that is the result of the analysis of documents or practices. This type of information is easier to transfer to new cases as:

- The context that is addressed (e.g. the type and severity of failures/problems to which a solution could be applied) is described;

- It is explicitly generated to be reused across cases; hence, it includes only relevant information;
- It represents a trustable source;

- The number of documents is limited compared to those capturing non-processed information.

Figure 9 integrates Fig. 8 and illustrates the steps to facilitate the reuse of service knowledge in the form of documentation.

Given the advantages of reusing processed information, a company is recommended to gather and analyse documentation from similar cases in order to generate a set of standard documents, which are easier to retrieve and reuse in new cases than unprocessed information. The RSK model takes it onset in moving knowledge from service to engineering design and also to be reused in service. The model takes into account the translation process that is required so that is knowledge is more easily reusable as identified from the analysis, e.g. the need for engineering designers to access the knowledge at component level, whereas the reuse of knowledge by other service engineers needs to be at the equipment level.

The model for reusing service knowledge (RSK model) illustrated in Fig. 9 represents a model that can be applied beyond the specific case as the type of knowledge it is targeted to, changes and issues from service, has been proved to be relevant for other engineering domain by a number of studies (e.g. Vianello and Ahmed-Kristensen 2012 comparative studies of engineering changes between the aerospace industry and oil drilling industry). Jagtap et al.'s (2007) research within the aerospace industry found that the transfer of knowledge from the service phase to the design phase within the aerospace industry was limited to knowledge of deterioration of components and highlighted the need for service knowledge for: maintenance and failure data, reliability, service instructions and lifecycle costs. Failure data are very much linked to changes and issues, as it is often the failure that creates the need for the engineering change, once the product is in service (rather than a solely focused upon product improvement). Wenger et al. (2002) describe the need to facilitate better knowledge sharing between the engineering and services units of the product development process for the automotive industry.

A number of studies in other domains to the oil drilling industry have highlighted the importance of transfer of service knowledge to design in the aerospace industry (Wong et al. 2007; Jagtap and Johnson 2011) and also in smaller-scale products (e.g. Doultsinou et al. (2009) with cases with vacuum pumps). Both highlight the need for transfer of knowledge from service to design, showing that this can enhance design through better knowledge of operating conditions. 


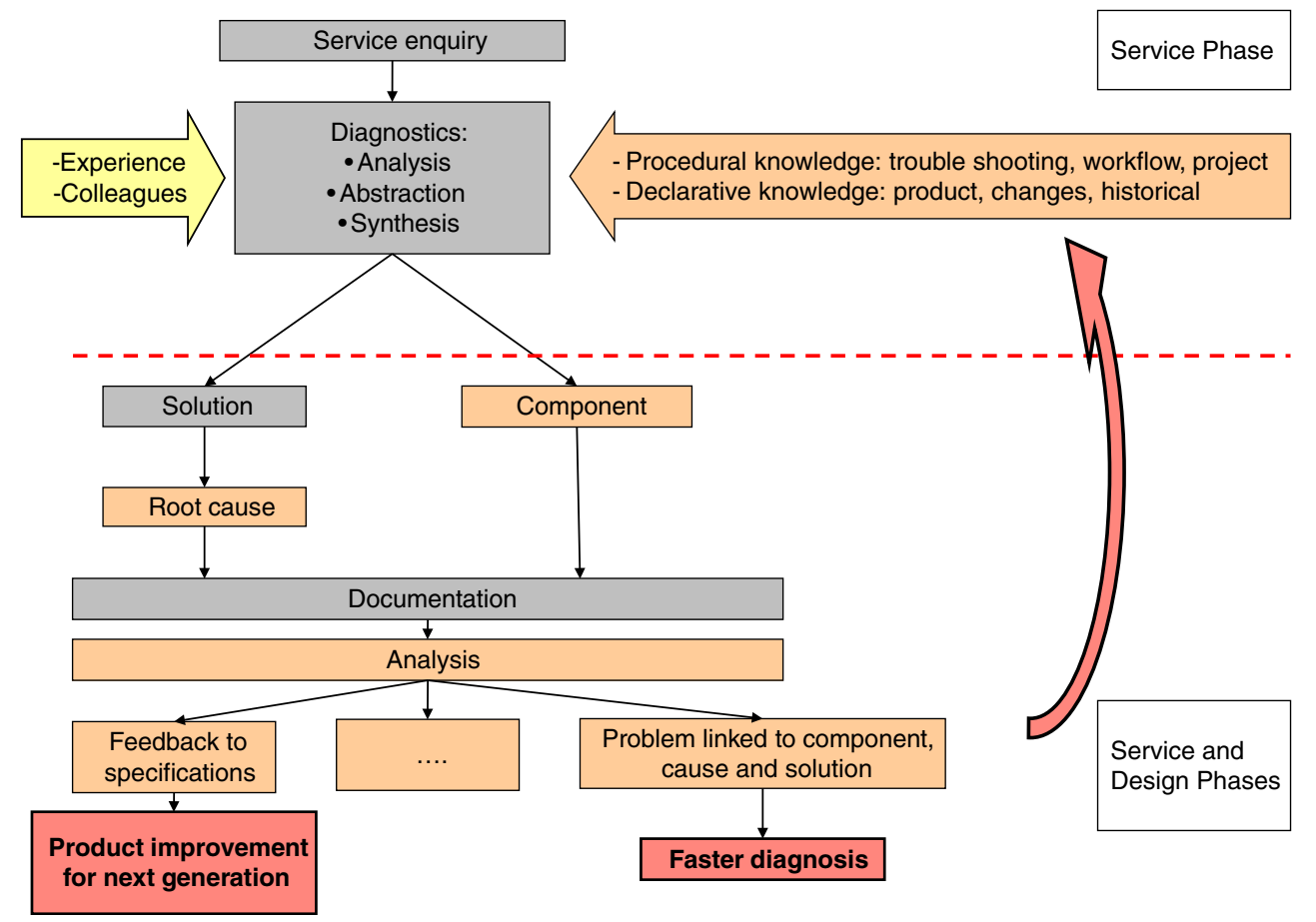

Fig. 9 Reusing service knowledge (RSK) model

\subsection{Selection of knowledge management processes}

The final stage of Kamara's framework defines the knowledge transfer processes associated with each migration path. The knowledge transfer mechanisms illustrated by Argote and Ingram (2000) could be used as guidelines to identify solutions suitable for each context, for instance by moving or modifying knowledge reservoirs.

The analysis of the case study showed that, without changing the organisational culture, when knowledge is transferred within the service phase, the process could include an active involvement of service engineers (pushing information into the reservoirs and pulling information from the reservoirs), whilst when knowledge from service is expected to be reused by engineering designers, a process for pushing information to designers should be developed. In the case of knowledge transferred across organisational boundaries, the knowledge management process also requires a translation phase, in order to take into account the differences between the backgrounds and subsequent needs of service engineers and engineering designers (Carlile 2004).

\section{Conclusion}

This paper described a research study focused upon the knowledge arising from the service phase of complex engineering products.
In the first part of the study (descriptive study), a case study approach was adopted and a case study was conducted within the context of a company supplying drilling equipment for the oil industry. The study investigated the knowledge relevant for engineering designers and service engineers and the extent to which this knowledge was transferred across departments. Knowledge about changes, issues and improvements was identified as the main type of knowledge from service that was of interest for both service engineers and engineering designers, acting effectively as a boundary object. However, despite the potential benefits through the reuse of this knowledge, such as the improvement to the next generation of products and the provision of more efficient support during service, the collaborating company did not implement any dedicated knowledge management strategy to achieve a systematic reuse of this knowledge. Instead, this knowledge was primarily transferred through personalisation strategies.

Although engineering designers found knowledge about changes, issues and improvements relevant for the design phase, they rarely retrieved available documentation from the knowledge repositories, instead preferring to contact directly senior positions at the operational side if necessary. The findings showed an imbalance in the transfer of knowledge between engineering designers and service engineers, e.g. more than $50 \%$ of instances regarding knowledge from service were pushed (hence made available) to the engineering designers without them actively requesting this knowledge. 
One of the implications of this is the engineering designers were overloaded with information, and it is not clear whether this information is reused. This knowledge was typically reported in a way that was suitable for service engineers to diagnose and reports service issues, but would require a new structure to facilitate its reuse during the design process and restructuring this knowledge was one of the concerns of the engineering designer. The findings highlighted the need to structure and translate knowledge to address the needs of the users, with the service engineers typically reporting knowledge at equipment level, whereas the engineering designers requiring this knowledge at component level.

On the contrary, service engineers' tended to pull information from the design phase implying that their requirements for information (from the design phase) were not fully fulfilled; they expressed the need to have access to more information. The service engineers were willing to share their knowledge across departments in order to improve the equipment design (seen from the high level of pushing of knowledge); in contrast, engineering designers were not likely to seek information from operation whilst designing a product. This resulted in the service engineers being the initiators of most of the communication with engineering designers, either by pushing information from the operation of machinery to engineering designers or by pulling the information they need from the design phase.

In the second part of the research study based upon the findings from the case study and reviewing a framework for developing a knowledge management strategy from the literature, the RSK (reusing service knowledge) model was proposed. The model describes a path to support the availability of knowledge about changes, issues and improvements from service in a form that is easy to apply to new contexts. The model aims to: (1) support engineering designers during the development of the next generation of equipment by providing information in a structure that is more accessible and includes recurrent issues and the root causes and ensure that knowledge is structured at a component level as well as equipment level; (2) facilitate the service provision through standard troubleshooting processing and suggesting solutions are implemented based upon past cases and therefore supporting a faster diagnosis of service issues.

Open Access This article is distributed under the terms of the Creative Commons Attribution License which permits any use, distribution, and reproduction in any medium, provided the original author(s) and the source are credited.

\section{References}

Aamodt A, Plaza E (1994) Case-based reasoning: foundational issues, methodological variations, and systems approaches. AI Commun 7(1):39-59
Ahmad N, Wynn D, Clarkson PJ (2013) Change impact on a product and its redesign process: a tool for knowledge capture and reuse. Res Eng Design 24(3):219-244

Ahmed S (2005) Encouraging reuse of design knowledge: a method to index knowledge. Des Stud 26(6):565-592

Ahmed S, Vianello G (2009) Transfer of service knowledge: a case from the oil industry. ICoRD, Bangalore, Jan 2009

Ahmed S, Wallace K, Blessing L (2003) Understanding the differences between how novice and experienced designers approach design tasks. Res Eng Des 14(1):1-11

Argote L, Ingram P (2000) Knowledge transfer: a basis for competitive advantage in firms. Organ Behav Hum Decis Process 82(1):150-169

Blackburn JD (1992) Time-based competition: white collar activities. Bus Horiz 35(4):96-101

Blessing L, Chakrabarti A (2009) DRM: a design research methodology. Springer, London

Carlile PR (2004) Transferring, translating, and transforming: an integrative framework for managing knowledge across boundaries. Organ Sci 15(5):555-568

Carter DE, Baker BS (eds) (1992) Concurrent engineering: the product development environment for the 1990s. AddisonWesley, Reading

Chua A, Lam W (2005) Why KM project fails: a multi-case analysis. J Knowl Manag 9(3):6-17

Doultsinou A, Roy R, Baxter D, Gao J, Mann A (2009) Developing a service knowledge reuse framework for engineering design. J Eng Des 20(4):389-411

Earl M (2001) Knowledge management strategies: toward a taxonomy. J Manag Inf Syst 18(1):215-233

Gilbert M, Cordey-Hayes M (1996) Understanding the process of knowledge transfer to achieve successful technological innovation. Technovation 16(6):301-312

Hansen MT, Nohria N, Tierney T (1999) What's your strategy for managing knowledge? Harv Bus Rev 77(2):106-116

Hargadon AB (1998) Firms as knowledge brokers: lessons in pursuing continuous innovation. Calif Manage Rev 40(3):209

Heisig P, Caldwell NHM, Grebici K, Clarkson PJ (2010) Exploring knowledge and information needs in engineering from the past and for the future-results from a survey. Des Stud 31(5):499-532

Jagtap S, Johnson A (2011) In-service information required by engineering designers. Res Eng Des 22(4):207-221

Jagtap S, Johnson A, Aurisicchio M, Wallace K (2007) In-service information required by engineering designers. In: International conference on engineering design, ICED'07, 28-31 Aug 2007

Jensen OK, Ahmed S (2009) Acceptance and divergence from engineering design procedures implicating knowledge flow. In: Proceedings of the ASME design engineering technical conference, DETC 2009, vol 8, pp 927-936

Kamara JM, Anumba CJ, Carrillo PM (2002) A CLEVER approach to selecting a knowledge management strategy

Khadilkar DV, Stauffer LA (1996) An experimental evaluation of design information reuse during conceptual design. J Eng Des 7(4):331

Lin L, Geng X, Whinston AB (2005) A sender-receiver framework for knowledge transfer. MIS Q 29(2):197-219

Lincke W (1995) Simultaneous engineering. Carl Hanser Verlag, Munich

Lucier CE, Torsilieri J (1997) Why knowledge programs fail: a CEO's guide to managing learning. In: Strategy and Business. Booz-Allen and Hamilton, New York, pp 14-28

March JG (1991) Exploration and exploitation in organizational learning. Organ Sci 2(1):71-87

McIntosh KG (1995) Implementing engineering data management solutions. World Cl Des Manuf 2(4):23-30 
McMahon C, Lowe A, Culley S (2004) Knowledge management in engineering design: personalization and codification. J Eng Des 15(4):307-325

Pawlowski SD, Robey D (2004) Bridging user organizations: knowledge brokering and the work of information technology professionals. MIS Q 28(4):645-672

Reichwald R, Picot A, Wigand RT (2010) Information, organization and management. Springer, Berlin

Robertson J (2003). Knowledge management for front-line staff. KM Column

Soderberg LG (1989) Facing up to the engineering gap. McKinsey Q (Spring):3-23

Storey J, Barnett E (2000) Knowledge management initiatives: learning from failure. J Knowl Manag 4(2):145-156

Terwiesch C, Loch CH (1999) Managing the process of engineering change orders: the case of the climate control system in automobile development. J Prod Innov Manage 16(2):160-172

Vianello G, Ahmed-Kristensen S (2012) A comparative study of changes across the lifecycle of complex products in a variant and a customised industry. J Eng Des 23(2):99-117

Vianello G, Xie Y, Ahmed-Kristensen S, Culley S, Vianello G, Xie Y, Ahmed-Kristensen S, Culley S (2010) Handling of in-service support: comparison of two case studies from complex industries. In: Proceedings of the 11th international design conference
Von Krogh G, Nonaka I, Aben M (2001) Making the most of your company's knowledge: a strategic framework. Long Range Plann 34(4):421-439

Wallace KM, Ahmed S, Bracewell RH (2005) Engineering knowledge management. In: Clarkson PJ, Eckert C (eds) Design process improvement - a review of current practice. Springer, London, pp 326-343

Wenger E (2000) Communities of practice and social learning systems. Organization 7(2):225-246

Wenger E, McDermott R, Snyder WM (2002) Cultivating communities of practice: a guide to managing knowledge. Harvard Business School Press Books, Boston, pp 1-4

Wong SC, Crowder RM, Wills GB, Shadbolt NR (2007) Informing preliminary design by incorporating service knowledge. In: International conference on engineering design, ICED 2007

Yin RK (1994) Case study research: design and methods, 2nd edn. Sage, Thousand Oaks

Zack MH (1999) Managing codified knowledge. Sloan Manag Rev 40(4):45-58

Zander U, Kogut B (1995) Knowledge and the speed of the transfer and imitation of organizational capabilities - an empirical-test. Organ Sci 6(1):76-92 